\title{
Pengaruh Pemberian Parasetamol Intravena untuk Mengurangi Nyeri Persalinan Kala I Fase Aktif
}

\author{
Juli Sitorus ${ }^{1}$, Ova Emilia², Detty Siti Nurdiati \\ ${ }^{1,2,3}$ Departemen Obstetri dan Ginekologi, Fakultas Kedokteran, Kesehatan Masyarakat dan Keperawatan, UGM \\ Korespondensi: juli.sitorus@gmail.com
}

Submisi: 16 Januari 2020; Revisi: 12 Mei 2020; Penerimaan: 14 Mei 2020

\begin{abstract}
ABSTRAK
Background: Labor was a physiological process, labor pain appeared from regularly uterine contraction, cervix distention and pressure to pelvic floor that stimulate free end nerves. Pain labor can influenced the mother, fetus and the progress of labor. There are various of effort to decrease pain labor by pharmacological or non pharmacological. The best therapy must be safe, effective, and minimal adverse effect to mother and fetus.

Objective: To evaluate the effect of $1000 \mathrm{mg}$ paracetamol intraveneous for pain relief in active labor versus $100 \mathrm{ml}$ saline water.

Method: In randomized controlled trial, with single blinded, 66 primigravid in active labor at RSUD Hj. ANNA LASMANAH Banjarnegara and RSUD Banyumas from November 2016 to January 2017. Sampels divided in two groups, paracetamol group $(n=33)$ and normal saline group ( $n=33$ ). The primary outcome was the efficacy of paracetamol to relief pain. Intensity of the pain measure by VAS (visual analogue scale), pain measured before drug administration, after 30 minutes, at 1, 2, 3, and 4 hours in both groups. The secondary outcomes include the adverse effect to the mother and baby in both group.

Results and Discussion: The reduction in pain score was significantly greater in paracetamol group than normal saline after 30 minutes, 1, 2, 3, and 4 hours after adiministration of the drug $(p<0.05)$. There was no adverse effect to mother and baby in both groups.

Conclusion: Paracetamol intravenous statistically significant decreasing mean pain score than normal saline and safe in active labor.
\end{abstract}

Keywords: Paracetamol; analgesia; active phase in labor

\section{ABSTRAK}

Latar Belakang: Persalinan merupakan proses fisiologis, nyeri timbul karena kontraksi uterus, peregangan servik dan penekanan dasar panggul memicu ujung saraf bebas. Nyeri dapat mempengaruhi keadaan ibu, janin dan kemajuan persalinan. Ada banyak B metode untuk mengurangi nyeri baik secara farmakologi atau non farmakologi. Analgesia yang terbaik bila dapat digunakan secara aman, efektif, mempunyai angka kepuasan yang tinggi serta efek samping terhadap ibu dan bayi minimal.

Tujuan: Mengetahui pengaruh parasetamol $1000 \mathrm{mg}$ intravena untuk mengurangi nyeri persalinan kala I fase aktif dibandingkan dengan NaCl $100 \mathrm{ml}$. Metode: Uji Klinis secara random (Randomized Clinical Trial), penyamaran tunggal (single blinded), 66 wanita primipara inpartu di RSUD Hj. ANNA LASMANAH dan RSUD Banyumas dari November 2016 sampai dengan Januari 2017, sampel dibagi dua kelompok yaitu parasetamol 33 sampel dan $\mathrm{NaCl} 33$ sampel. Hasil utama yang dinilai adalah penurunan re-rata skor VAS (Visual Analogue Scale) sebelum perlakuan dan setelah 30 menit, 1 jam, 2 jam, 3 jam dan 4 jam perlakuan. Pengaruh lainnya yaitu efek samping yang timbul pada kedua kelompok.

Hasil dan Pembahasan Terdapat perbedaan bermakna re-rata skor VAS pada kelompok parasetamol dibandingkan kelompok NaCl setelah perlakuan. Re-rata skor VAS pada kelompok parasetamol lebih rendah dibandingkan kelompok $\mathrm{NaCl}$ setelah 30 menit, 1 jam, 2 jam, 3 jam dan 4 jam (p<0.05). Tidak terdapat efek samping pada ibu dan janin pada kedua kelompok.

Kesimpulan: Parasetamol intravena siginifikan secara statistik menurunkan re-rata skor nyeri persalinan dibandingkan $\mathrm{NaCl}$ dan tidak terdapat efek samping.

Kata kunci: Parasetamol; analgesia; fase aktif persalinan 


\section{PENDAHULUAN}

Proses persalinan biasanya akan mengakibatkan rasa tidak nyaman dan nyeri. Intensitas nyeri sangat individual, tergantung dari faktor fisik meliputi keadaan umum, usia, berat badan lahir bayi, dan faktor psikologi seperti emosi, motivasi, dan dukungan sosial, serta budaya dari ibu. ${ }^{1,2}$ Nyeri yang berlebihan dapat mempengaruhi sistemik ibu dan keadaan janin, hal ini disebabkan oleh karena nyeri dapat menstimulasi sistim pernafasan, kardiovaskular, saraf pusat, dan fungsi saraf otonom neuroendokrin, serta gangguan keseimbangan metabolik pada ibu. Perubahan pada sistemik ibu akan berpengaruh pada janin, bayi baru lahir, serta mempengaruhi intensitas dan koordinasi kontraksi uterus sehingga dapat mempengaruhi lamanya persalinan. ${ }^{1,2,3}$

Meskipun analgesia regional efektif untuk mengatasi nyeri persalinan, terdapat efek samping seperti demam pada ibu, hipotensi, retensi urin, peningkatan penggunaan oksitosin, kala dua persalinan yang lebih lama, mengakibatkan biaya yang lebih besar dan peningkatan jumlah persalinan dengan menggunakan alat. ${ }^{4,5,6,7,8}$ Selain itu juga dapat terjadi cedera saat punksi lumbal, hematom epidural, apnea oleh karena kesalahan penggunaan dan dosis obat serta keadaan anestesi total akibat injeksi intratekal yang salah. . $, 5,9,10^{2}$

Penggunaan golongan opioid sendiri untuk penatalaksanaan nyeri pada persalinan masih diperdebatkan oleh karena efek samping yang bisa terjadi pada ibu dan janin. Efek samping yang sering diakibatkan oleh golongan opioid seperti mual, muntah, pusing, merasa lemas, melambatnya pengosongan lambung, disforia, mengantuk, dan hipoventilasi. ${ }^{2,5,8}$ Selain itu pemberian golongan opiod juga dapat mengakibatkan efek samping ke janin seperti depresi pernafasan, non reassuring fetal heart rate (NRFHR), dan melemahnya tonus otot saat bayi lahir. ${ }^{5,8}$

Parasetamol sejak dulu digunakan secara luas sebagai analgesia pengganti jika terdapat kontraindikasi pada pemberian aspirin. ${ }^{10}$ Pemberian parasetamol pada dosis terapi cukup aman pada semua usia kehamilan dan saat laktasi. ${ }^{11}$ Hal ini sesuai dengan hasil penelitian sebelumnya yang dilakukan Elbohoty et al. (2012) yang menyatakan parasetamol efektif dan aman digunakan sebagai analgesia pada persalinan.

Berdasarkan hal tersebut diatas, maka penulis berkeinginan melakukan penelitian mengenai pengaruh parasetamol sebagai analgesia dalam persalinan untuk mengetahui keefektifan serta keamanannya dalam mengurangi nyeri persalinan. Adapun penelitian tentang pengaruh pemberian parasetamol untuk mengurangi nyeri persalinan kala I fase aktif sepengetahuan peneliti belum pernah dilakukan di Indonesia.

\section{METODE}

Penelitian ini merupakan penelitian acak terkontrol (randomized controlled trial), dengan penyamaran tunggal (single blinded). Populasi pada penelitian ini adalah primigravida inpartu kala I fase aktif yang direncanakan persalinan vaginal di ruang bersalin RSUD Banyumas dan RSUD Hj. ANNA LASMANAH Banjarnegara periode November 2016 sampai Januari 2017. Subyek yang diikutkan dalam penelitian ini adalah wanita yang memenuhi kriteria inklusi sebagai berikut: primigravida, usia kehamilan 37-41 minggu, janin tunggal, hidup, presentasi kepala dan rencana persalinan vaginal, persalinan kala I fase aktif dengan pembukaan servik $3-5 \mathrm{~cm}$. Kriteria eksklusi penelitian ini adalah riwayat penyakit hati atau ginjal, ibu dengan penyakit sistemik seperti hipertensi, hipertiroid, jantung, atau paru, riwayat induksi persalinan sebelumnya, ketuban pecah dini, disproporsi kepala panggul, riwayat alergi atau hipersensifitas terhadap parasetamol, kehamilan dengan kelainan kongenital pada janin, dan riwayat pemakain analgesia. Pasien yang memenuhi kriteria inklusi dan eksklusi dibagi menjadi 2 kelompok yaitu kelompok parasetamol: sampel yang mendapatkan parasetamol intravena $1000 \mathrm{mg}$ dalam $100 \mathrm{ml}$ cairan fisiologis, dan kelompok $\mathrm{NaCl}$ yaitu sampel yang mendapatkan cairan $\mathrm{NaCl}$ fisiologis $100 \mathrm{ml}$.

Hasil utama dari penelitian ini adalah pengaruh pemberian parasetamol intravena dalam mengurangi nyeri persalinan kala I fase aktif. Nyeri persalinan diukur dengan menggunakan visual analogue scale (VAS), yang diperiksa sebelum pemberian perlakuan, setelah 30 menit, 1 jam, 2 jam, 3 jam dan 4 jam perlakuan. Hasil lain yang 
dinilai pada penelitian ini adalah efek samping yang timbul setelah perlakuan.

Analisis statistik meliputi uji homogenitas, uji normalitas, uji parametrik: uji-T perbandingan rerata 2 kelompok saling bebas (Independent T Test) pada data yang terdisitribusi normal. Data yang tidak terdistribusi normal dilakukan uji non parametrik: uji Mann-Whitney. Analisis data menggunakan SPSS versi 16.

\section{HASIL DAN PEMBAHASAN}

Sampel penelitian yang diperoleh sebanyak 66 primigravida inpartu yang memenuhi kriteria inklusi dan eksklusi, sampel terbagi dua kelompok yaitu 33 sampel kelompok parasetamol dan 33 sampel kelompok $\mathrm{NaCl}$. Saat proses persalinan pada kelompok parasetamol sebanyak 15 sampel $(45,4 \%)$ hanya mendapatkan satu kali pemberian parasetamol, sedangkan 18 sampel (54,5\%) mendapatkan dua kali pemberian parasetamol. Pada kelompok $\mathrm{NaCl}$ sebanyak 13 sampel $(39,4 \%)$ hanya mendapatkan satu kali pemberian $\mathrm{NaCl}$ dan sebanyak $20(60,6 \%)$ sampel mendapatkan dua kali pemberian $\mathrm{NaCl}$.

Tabel 1. Uji homogenitas variabel luar kelompok Parasetamol dan $\mathrm{NaCl}$

\begin{tabular}{lccc} 
Variabel & $\begin{array}{c}\text { Parasetamol } \\
\text { Mean } \pm \text { SD }\end{array}$ & NaCl & Mean \pm SD \\
Usia & $22,79 \pm 3,65$ & $23,33 \pm 4,57$ & $0,330^{*}$ \\
Usia Kehamilan & $39,15 \pm 1,45$ & $39,36 \pm 1,08$ & $0.854^{*}$ \\
Berat Bayi Lahir & $3081,82 \pm 259,45$ & $3008,67 \pm 297,81$ & $0,370^{*}$ \\
IMT & $26,3 \pm 1,86$ & $26,09 \pm 2,65$ & $0.708^{*}$ \\
\hline
\end{tabular}

Tabel 1 menunjukkan uji homogenitas subyek penelitian, dan menunjukkan bahwa subyek penelitian homogen dan sebanding. Variabelvariabel penelitian yaitu: usia, usia kehamilan, berat bayi lahir dan IMT, pada kedua kelompok penelitian tidak terdapat perbedaan bermakna ( $p>0,05)$. Hasil ini menunjukkan bahwa data terdistribusi secara merata sebelum penelitian. Sehingga kemungkinan adanya bias dari variabel luar dapat dihindari.

Tabel 2. Nilai Re-rata dan uji normalitas kelompok Parasetamol dan $\mathrm{NaCl}$

\begin{tabular}{|c|c|c|c|c|c|c|}
\hline \multirow{3}{*}{ Variabel } & \multicolumn{6}{|c|}{ Kelompok } \\
\hline & \multicolumn{3}{|c|}{ Paracetamol } & \multicolumn{3}{|c|}{$\mathrm{NaCl}$} \\
\hline & $\mathrm{n}$ & Mean $\pm S D$ & $\mathrm{P}$ & $n$ & Mean \pm SD & $\mathrm{P}$ \\
\hline \multicolumn{7}{|l|}{ Skor VAS } \\
\hline Sebelum perlakuan & 33 & $6,94 \pm 1,46$ & $0,137^{*}$ & 33 & $6,79 \pm 1,49$ & $0,153^{*}$ \\
\hline 30 menit & 33 & $6,42 \pm 1,39$ & $0,075^{*}$ & 33 & $7,18 \pm 1,08$ & 0,018 \\
\hline 1 jam & 33 & $5,97 \pm 1,26$ & $0,085^{*}$ & 33 & $7,27 \pm 1,23$ & $0,068^{*}$ \\
\hline 2 jam & 33 & $6,03 \pm 1,26$ & $0,085^{*}$ & 33 & $7,97 \pm 1,16$ & $0,062^{*}$ \\
\hline 3 jam & 33 & $6,48 \pm 1,26$ & 0,043 & 33 & $7,94 \pm 1,19$ & 0,005 \\
\hline 4 jam & 32 & $6,69 \pm 1,53$ & $0,073^{*}$ & 30 & $8,00 \pm 1,26$ & $0,71^{*}$ \\
\hline Lama Kala I sejak perlakuan (Jam) & 33 & $6,89 \pm 2,30$ & $0,188^{*}$ & 33 & $7,18 \pm 2,66$ & $0,200 *$ \\
\hline
\end{tabular}

*signifikan ( $p>0,05)$ 
Tabel 2. menunjukkan uji normalitas pada kedua kelompok. Uji normalitas untuk menentukan uji selanjutnya yang akan dilakukan dalam membandingkan nilai re-rata kedua kelompok apakah menggunakan uji parametrik atau uji non parametrik. Uji parametrik dilakukan pada variabel dengan data terdistribusi normal $(p>0,05)$. Apabila data tidak terdistribusi normal $(p<0,05)$ maka dilakukan uji non parametrik. Dari tabel 2. data yang terdistribusi normal yaitu: VAS sebelum perlakuan, VAS setelah 1 jam, VAS setelah 2 jam dan VAS setelah 4 jam, serta lama kala I sejak perlakuan. VAS setelah 30 menit dan VAS setelah 3 jam tidak terdistribusi normal. Untuk membandingkan rerata kedua kelompok pada data yang terdistribusi normal dilakukan dengan uji parametrik yaitu: Uji-T perbandingan re-rata dua kelompok saling bebas (Independent T-Test) sedangkan pada data yang tidak terdistribusi normal dilakukan dengan uji noparametrik perbandingan re-rata dua kelompok saling bebas yaitu uji Mann-Whitney.

Tabel 3. Uji Mann-Whitney kelompok Parasetamol dan $\mathrm{NaCl}$

\begin{tabular}{|c|c|c|c|c|c|}
\hline Variabel & $\mathrm{n}$ & $\begin{array}{l}\text { Skor Nyeri } \\
\text { Mean } \pm S D\end{array}$ & $\begin{array}{l}\text { Mean } \\
\text { Rank }\end{array}$ & Z & $P$ \\
\hline \multicolumn{6}{|l|}{ VAS setelah 30 menit } \\
\hline Parasetamol & 33 & $6,42 \pm 1,39$ & 24,48 & & \\
\hline & & & & 2.174 & $0,030^{*}$ \\
\hline $\mathrm{NaCl}$ & 33 & $7,18 \pm 1,08$ & 38,52 & & \\
\hline \multicolumn{6}{|l|}{ VAS setelah 3 jam } \\
\hline Parasetamol & 33 & $6,03 \pm 1,26$ & 24,58 & & \\
\hline & & & & 3,849 & $0,000^{*}$ \\
\hline $\mathrm{NaCl}$ & 33 & $7,97 \pm 1,16$ & 42,42 & & \\
\hline
\end{tabular}

Re-rata skor VAS sebelum perlakuan kelompok parasetamol dan $\mathrm{NaCl}$ tidak berbeda bermakna. $(p>0,05)$. Hal ini menunjukkan bahwa sebelum pemberian parasetamol atau $\mathrm{NaCl}$ intensitas nyeri pada kedua kelompok sebanding.
Adapun re-rata skor VAS 1 jam, 2 jam, dan 4 jam pada kedua kelompok berbeda bermakna dengan nilai $p=0,000(p<0,05)$. Sedangkan re-rata lama kala I sejak perlakuan pada kelompok parasetamol dan $\mathrm{NaCl}$ tidak berbeda bermakna dengan nilai $\mathrm{p}=0,640$ $(p>0,05)$.

Tabel 4. Uji Mann-Whitney kelompok Parasetamol dan $\mathrm{NaCl}$

\begin{tabular}{|c|c|c|c|c|c|}
\hline Variabel & $n$ & $\begin{array}{l}\text { Skor Nyeri } \\
\text { Mean } \pm S D\end{array}$ & $\begin{array}{l}\text { Mean } \\
\text { Rank }\end{array}$ & Z & $P$ \\
\hline \multicolumn{6}{|l|}{ VAS setelah 30 menit } \\
\hline Parasetamol & 33 & $6,42 \pm 1,39$ & 24,48 & \multirow{3}{*}{2.174} & \multirow{3}{*}{$0,030^{*}$} \\
\hline & & & & & \\
\hline $\mathrm{NaCl}$ & 33 & $7,18 \pm 1,08$ & 38,52 & & \\
\hline \multicolumn{6}{|l|}{ VAS setelah 3 jam } \\
\hline Parasetamol & 33 & $6,03 \pm 1,26$ & 24,58 & \multirow{3}{*}{3,849} & \multirow{3}{*}{$0,000^{*}$} \\
\hline & & & & & \\
\hline $\mathrm{NaCl}$ & 33 & $7,97 \pm 1,16$ & 42,42 & & \\
\hline
\end{tabular}


Tabel 4. Menunjukkan skor VAS dan mean rank pada uji Mann-Whitney pada kedua kelompok setelah 30 menit dan 3 jam perlakuan. Mean rank pada kedua kelompok setelah 30 menit dan 3 jam berbeda bermakna $p<0,005$.

Hasil lain dari penelitian ini yaitu tidak terdapat efek samping pada ibu dan janin seperti mual, muntah, pusing, urtikaria atau gangguan denyut jantung janin pada kedua kelompok.

Gambar 1. Menunjukkan grafik re-rata skor VAS pada kedua kelompok, dari gambar menunjukkan re-rata skor VAS pada kelompok parasetamol berada dibawah atau lebih rendah dibandingkan pada kelompok $\mathrm{NaCl}$.

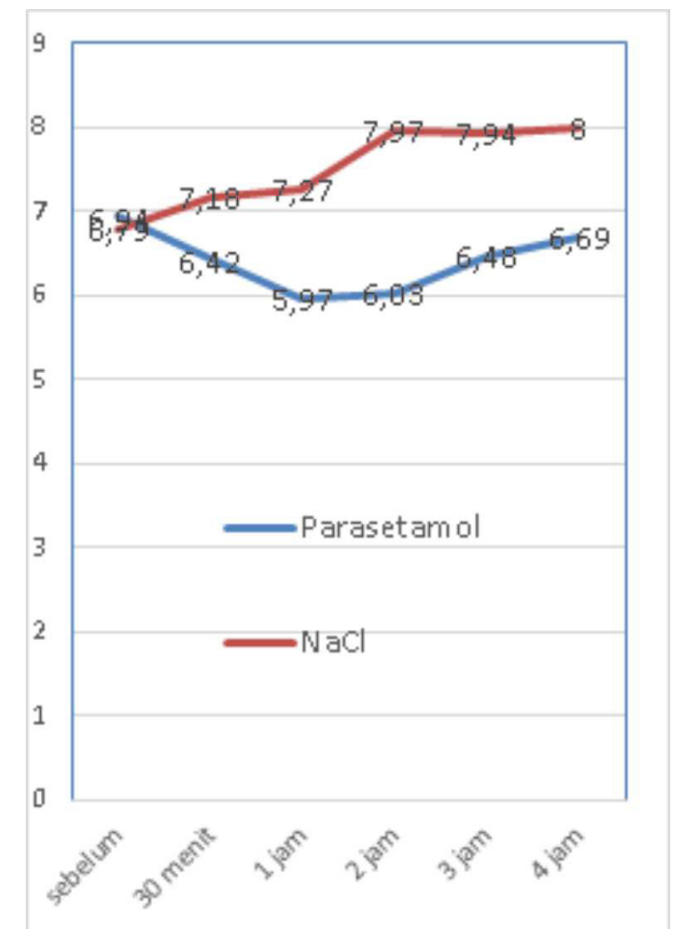

Gambar 1. Re-rata skor VAS menurut waktu pemeriksaan

Uji homogenitas terhadap variabel luar yaitu: umur, paritas, usia kehamilan dan berat badan bayi saat lahir kedua kelompok menunjukkan bahwa proporsi dan distribusi dari sampel penelitian tidak berbeda bermakna $(p>0,05)$. Hal ini menunjukkan bahwa variabel luar dari sampel pada penelitian ini sebanding sebelum perlakuan.

Dari hasil uji normalitas terhadap variabel didapatkan bahwa data variabel VAS sebelum perlakuan, VAS setelah 1 jam, VAS setelah 4 jam, dan lama kala I sejak perlakuan terdistribusi secara normal $(p>0,05)$. Data variabel VAS setelah 30 menit dan 3 jam, tidak terdistribusi normal $(p<0,05)$.

Dari hasil uji $\mathrm{T}$ diperoleh, rata-rata skor VAS antara kelompok parasetamol dan $\mathrm{NaCl}$ sebelum penelitian tidak ada perbedaan yang bermakna $p=0,678 \quad(p>0,05)$. Hasil ini menunjukkan bahwa sebelum diberikan perlakuan intensitas nyeri pada kedua kelompok tidak berbeda.

Dari tinjauan pustaka mengenai dosis dan bioavailabilitas parasetamol intravena sejak diberi intervensi sampai memberikan efek analgesia (onset of action) membutuhkan waktu sekitar 5-10 menit, sedangkan lama dari pemberian agar mencapai kadar puncak di plasma sekitar 15 menit. Adapun waktu paruh (plasma half life) dari parasetamol intravena sekitar 2-3 jam, sedangkan lamanya efek parasetamol di dalam tubuh sekitar 4-6 jam.

Dari hasil uji $\mathrm{T}$ dan Mann-Whitney pada penelitian ini, perbandingan re-rata skor VAS setelah 30 menit, 1 jam, 2 jam, 3 jam dan 4 jam pada kedua kelompok, secara statistik berbeda bermakna dengan nilai $p<0,05$, hasil ini menunjukkan bahwa pemberian parasetamol efektif menurunkan skor rata-rata VAS sejak menit ke-30 sampai dengan setelah 4 jam pemberian. Hasil ini berbeda dari penelitian yang dilakukan oleh Elbohoty et al. (2012) dimana pada penelitian tersebut didapatkan parasetamol hanya efektif selama 2 jam, sedangkan pada jam ke-3 dan ke-4 tidak efektif. Kemungkinan perbedaan ini terkait perbedaan re-rata IMT, dimana pada pada penelitian tersebut re-rata IMT kelompok parasetamol 30,15 $\pm 3,74$, sedangkan pada penelitian ini IMT lebih rendah $26,3 \pm 1,86$. Dalam hal ini dosis parasetamol yang diberikan sama yaitu 1000 mg, sehingga kemungkinan efek analgesia dari parasetamol lebih lama pada penelitian ini.

Menurut IEE, et al. (2003) bahwa suatu analgesia dikatakan signifikan secara klinis menurunkan skor nyeri menurut persepsi nyeri pasien jika analgesia dapat menurunkan re-rata skor VAS minimal $3 .{ }^{15}$ Selain itu nilai VAS $<4$ dianggap sebagai tingkat nyeri yang rendah dan digunakan sebagai target untuk tatalaksana analgesia. Nilai VAS $>4$ dianggap nyeri sedang menuju berat sehingga pasien merasa tidak nyaman dan perlu diberikan obat analgesia tambahan/ penyelamat (rescue analgetic). ${ }^{16}$ 
Pada penelitian ini didapatkan bahwa perbedaan re-rata (mean difference) skor VAS pada parasetamol dibandingkan $\mathrm{NaCl}$ masih kurang dari 3 atau belum signifikan secara klinis walaupun secara statistik signifikan. Selain itu juga re-rata skor VAS setelah pemberian parasetamol masih $>4$, sehingga masih pada tahapan nyeri sedang dan berat yang masih membutuhkan analgesia tambahan.

Hasil lain dari penelitian ini adalah tidak didapatkan keluhan atau efek samping yang timbul seperti mual, muntah dan pusing atau urtikaria, hasil ini sama dengan beberapa penelitian sebelumnya.

Kekuatan penelitian ini adalah penggunaan penyamaran tunggal dan penggunaan metode pengukuran yang valid dengan menggunakan VAS, sehingga kemungkinan bias dapat dikurangi.

Kelemahan penelitian ini adalah persepsi nyeri tiap orang yang berbeda yang tidak dapat dikontrol peneliti, dan penilaian skor nyeri yang dilakukan oleh banyak orang. Untuk mengurangi bias, peneliti sudah melatih dan memberi penjelasan pada semua operator yang ikut dalam prosedur tindakan dan penilaian skor nyeri pada penelitian ini.

\section{KESIMPULAN DAN SARAN}

Efek analgesia dari parasetamol siginifikan secara statistik mengurangi skor nyeri persalinan kala I fase aktif setelah 30 menit, 1 jam, 2 jam, 3 jam dan 4 jam pemberian dibandingkan dengan $\mathrm{NaCl}$ namun secara klinis belum signifikan dan masih membutuhkan analgesia tambahan jika diperlukan. Tidak didapatkan efek samping seperti mual, muntah, pusing atau urtikaria pada kedua kelompok. Efek samping pada janin tidak ditemukan pada kedua kelompok.

Diperlukan penelitian lebih luas terhadap pengaruh parasetamol pada keadaan sistemik ibu dan bayi untuk mengetahui lebih mendalam tentang pengaruh parasetamol.

\section{DAFTAR PUSTAKA}

1. Cunningham, F.G., Leveno, K.J., Bloom, S.L., Hauth J.C., Rouse D.J., Catherine Y.S., 2014. Williams Obstetrics, $24{ }^{\text {nd }}$ ed. New York: McGraw-Hill Medical Publising Division, 408-432; 433-454; 504 - 522.
2. Leksana, E. dan Adipradja K., 2013. Manajemen nyeri persalinan. In: Bisri, T., Wahjoeningsih, S., Suwondo, B.S. Anestesi obstetri. Bandung: Saga Olahcitra, 315354.

3. Lucero, J.M., and Rollins, M.D., 2011. Obstetrics. In: Miller, R.D., Pardo, M.C. Basics of anesthesia. Philadelphia: Elseiver saunders, 514-545

4. O'Sullivan, G., 2009. Non neuraxial analgesic techniques. In: Bucklin, A.B., Gambling, D.R., Wlody, D.J. Obstetric anesthesia. Philadelphia: Lippincott williams and wilkins, 131-141

5. Schlichter, R.A. and Arkoosh, V., 2012. Analgesia and anesthesia. In: Berghella, V. Obstetric evidence based guidelines. London: Informa healthcare, 105115

6. Morgan, G.E., Mikhail, M.S., Murray, M.J., 2006. Obstetric anesthesia. In: Morgan, G.E., et al. Clinical Anesthesiology, $4^{\text {th }}$ ed. New York: McGraw-Hill Companies, 890-921.

7. Somuah, A.M., Smyth, R.M., Jones, I., 2011. Epidural for pain in labour. Cochrane library. Available from: http://www.cochrane.org/CD000331/PREG epidurals-for-pain-relief-in-labour [ 13 Maret 2016]

8. Campbell, D.C., and Bucklin, B.A., 2009. Impact of analgesia on labor and delivery outcomes. In: Bucklin, A.B., Gambling, D.R., Wlody, D.J. A practical approach to obstetric anesthesia. Philadelphia: Lippincott williams and wilkins, 169-184.

9. Segal, S., 2009. Choice of neuraxial analgesia and local anesthetics. In: Bucklin, A.B., Gambling, D.R., Wlody, D.J. A practical approach to obstetric anesthesia. Philadelphia: Lippincott williams and wilkins, 143-167.

10. Gupta, S., Kumar, A., Singhal, H., 2006. Acute painlabour analgesia. Indian J. Anaesth. Available from: http://ijaweb.org [1 oktober 2015]

11. Bennett, P.N. \& Brown, M.J., 2008. Clinical pharmacology, $10^{\text {th }}$ ed. Spain: Churcil living stone elseiver, 258-260.

12. Briggs, G.G., Freeman, R.G., Yaffe, S.J., 2008. Drugs in pregnancy and lactation. $8^{\text {th }} \mathrm{ed}$. Philadeplhia: Lippincott williams and wilkins, 10-15.

13. Elbohoty et al., 2012. Intravenous Infussion of paracetamol versus intravenous pethidine as an intrapartum analgesic in the first stage of labor. International Journal Gynaecology and Obstetrics. Available from: http://www.sciencedirect.com/ science/article/pii/S0020729212001427 [1 oktober 2015]

14. Twycross, R., Pace, V., Mihalyo, M., and Wilcock A., 2013. Theraupetic reviews: Acetaminophen (Parasetamol). Journal of pain and symptom management. Available from: http://www.dx.doi. 
org/10.1016/j.jpainsymman.2013.08.001 [15 Maret 2016]

15. Lee, J.S., et al., 2003. Clinically important change in the visual analogue scale adequate pain control. Wiley online library. Available from: http://
www.onelibrary.wiley.com/doi/10.1197/SI0696563(03)00372-5/pdf. [2 February 2017]

16. Fillingim, R.B., 2001. Pain measurement in humans. In : Holcroft A, Jaggar S, editors. Core topics in pain. Cambridge University New York: IASP Press.1-7. 